\title{
Total Synthesis of Illisimonin A
}

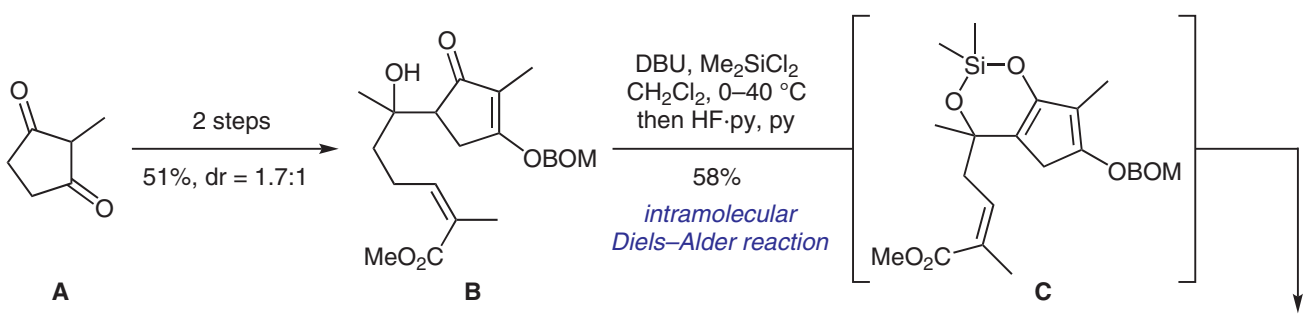

Synthesis of Natural

Products and

Potential Drugs
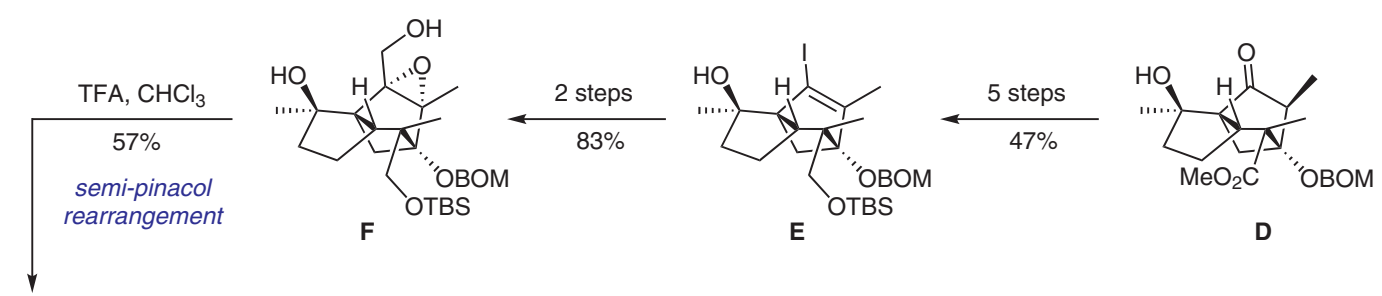

\section{Key words}

illisimonin A

semi-pinacol rearrangement

intramolecular Diels-Alder reaction

C-H oxidation

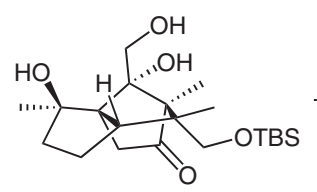

G

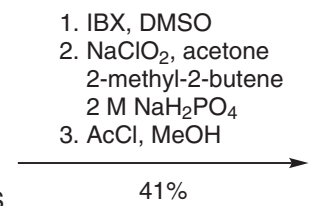

2. $\mathrm{NaClO}_{2}$, aceto

$41 \%$

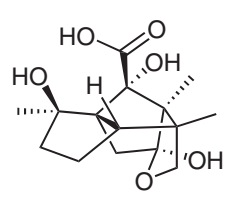

H
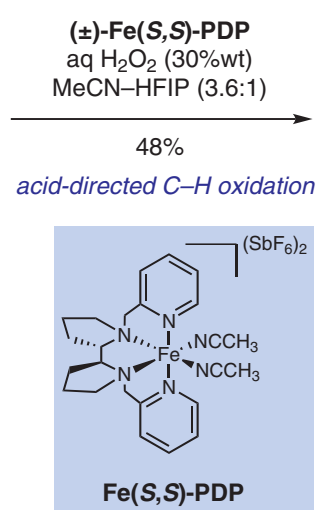

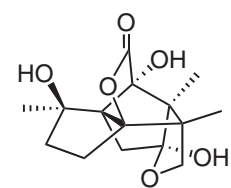

( \pm )-Illisimonin A
Significance: Burns and Rychnovsky report on the first total synthesis of illisimonin A, a sesquiterpenoid isolated from the fruits of Illicium simonsii. The combination of an intramolecular Diels-Alder reaction with a semi-pinacol rearrangement enables the rapid access of the target molecule's core structure. Using a resolution strategy, the authors are also able to produce enantioenriched (-)-ilisimonin A.
Comment: Enone $\mathbf{B}$ is generated from simple starting materials. A 1,3-dioxa-2-silacyclohexenetemplated Diels-Alder reaction yields the congested intermediate $\mathbf{D}$. Functional group interconversion leading to epoxide $\mathbf{F}$ pave the route for the crucial semi-pinacol rearrangement. Ultimately, functional group interconversions and a final directed $\mathrm{C}-\mathrm{H}$ oxidation give rise to the natural product. 